\title{
An eleven-year retrospective hospital-based study of epidemiological data regarding human strongyloidiasis in northeast Thailand
}

\author{
Thidarat K. Prasongdee ${ }^{1}$, Pokkamol Laoraksawong ${ }^{2}$, Wanida Kanarkard ${ }^{3}$, Ratthaphol Kraiklang², \\ Kraisit Sathapornworachai ${ }^{1}$, Sureeporn Naonongwai ${ }^{1}$, Porntip Laummaunwai ${ }^{1}$, Oranuch Sanpool ${ }^{1,4}$, \\ Pewpan M. Intapan ${ }^{1,4}$ and Wanchai Maleewong ${ }^{1,4^{*}}$
}

\begin{abstract}
Background: Human strongyloidiasis is a chronic and persistent gastrointestinal disease caused by infection with soil-transmitted helminths of the genus Strongyloides. The aim of this research was to obtain diagnostic prevalence regarding strongyloidiasis in northeast Thailand through a hospital-based study.

Methods: Patients' demographic data and the results of stool examinations conducted using the formalin ethyl acetate concentration technique were collected from the parasitology laboratory records at Srinagarind Hospital in Khon Kaen, Thailand. The relevant information from years 2004 to 2014 was collected and descriptively analyzed.

Results: Of a total of 22,338 patients, 3889 (17.4\%) had stool samples that tested positive for Strongyloides larvae. The highest prevalence was $22.8 \%(95 \% \mathrm{Cl}=19.6-26.2 \%)$ in the year 2004. This percentage progressively decreased, reaching $11.2 \%(95 \% \mathrm{Cl}=10.2-12.4 \%)$ in 2013 and remaining stable at $12.9 \%(95 \% \mathrm{Cl}=11.8-14.1 \%)$ in 2014. Males (2741 cases) had double the positivity rate of females (1148 cases). The prevalence of infection was highest (25.9\%; $95 \% \mathrm{Cl}=24.5-27.3 \%)$ among patients that were $51-60$ years of age.

Conclusions: Areas endemic for strongyloidiasis should be emphasized under the national helminth control program and health education campaigns. Nationwide assessments should also be performed regarding Strongyloides infection, including risk factors, treatment, and prevention. The diagnostic laboratory data presented here identify the geographical focus of disease to be the northeastern region of the country. Further targeted surveillance using more sensitive methods will almost certainly reveal a higher individual disease burden than found in this report.
\end{abstract}

Keywords: Prevalence, Strongyloidiasis, Hospital-based study, Thailand

\section{Background}

Human strongyloidiasis is a soil-transmitted helminthiasis caused by two species of the genus Strongyloides; Strongyloides stercoralis and Strongyloides fuelleborni $[1,2]$. While S. fuelleborni, a zoonotic helminth, is found in Africa and Papua New Guinea, S. stercoralis is widespread throughout

\footnotetext{
* Correspondence: wanch_ma@kku.ac.th

${ }^{1}$ Department of Parasitology, Faculty of Medicine, Khon Kaen University, Khon Kaen, Thailand

${ }^{4}$ Research and Diagnostic Center for Emerging Infectious Diseases, Mekong Health Science Institute, Khon Kaen University, Khon Kaen, Thailand

Full list of author information is available at the end of the article
}

the world, particularly in Latin America, Southeast Asia, Sub-Saharan Africa, northern Australia, and some parts of the southeastern United States [3].

Strongyloides stercoralis has a distinct free-living lifecycle in soil, allowing reproduction and amplification in the direct environment into which an infected person defecates. The disease has spread to areas all over the world, especially tropical and subtropical areas, most likely due to it having been transported with the migration of its human hosts. The worm's auto-infective lifecycle is the primary reason for its long term persistence in the human host. Thailand is located in the tropical 
zone and the high-temperatures are one of the risk factors associated with a high prevalence of $S$. stercoralis infection [4]. Studies (both community-based and hospital-based) have shown strongyloidiasis prevalence in Thailand to range from $2.5 \%$ to $33.3 \%$ [5-9]. The variations in the prevalence data can possibly be attributed to variations in populations and examination methods. Examination methods included direct simple smear, the formalin ethyl acetate concentration technique (FECT), and the agar plate culture (APC) method which exhibit different sensitivity in detecting the infection [5-9]. Furthermore, the hospitalbased studies revealed a higher prevalence of $S$. stercoralis infection than the community-based studies. This finding may be attributed to hospital-based studies using stool examination techniques with a higher sensitivity [2].

Srinagarind Hospital is a medical school and tertiary hospital which uses the FECT for parasite examination. Although the FECT has a lower overall sensitivity for the detection of strongyloidiasis than methods such as PCR, agar plate culture, or serology, for clinical purposes, it is sufficient and effective in the diagnosis of symptomatic individuals with larval burdens sufficiently high to be detected by this method [10]. Moreover, as patients who visited Srinagarind Hospital came from different provinces in the northeastern region of Thailand, our hospital-based study may provide insight into the region-wide distribution of strongyloidiasis, as well as other epidemiological data. This paper describes an eleven-year hospital-based study on the diagnostic prevalence of Strongyloides-infected patients in Srinagarind Hospital, a tertiary hospital in northeast Thailand.

\section{Methods}

Laboratory records were reviewed of patients seeking medical treatment in Srinagarind Hospital from 2004 to 2014. The routine fecal examination employed in the laboratory was the in-house FECT [11]. While some patients received several FECT examinations due to having visited the hospital multiple times, only one record was analyzed and included in this study. Data on gender, age, residence, and presence of Strongyloides larva were collected and analyzed using descriptive statistics with STATA package version 10.1 (StataCorp LLC, College Station, TX).

\section{Results}

A total of 22,338 patient records from 2004 to 2014 were collected. Of these patients, $17.4 \%$ (95\%CI $=16.9-$ $17.9 \%)$ were found to be positive for S. stercoralis. The diagnostic prevalence of infection was highest in 2004 at $22.8 \%(95 \% \mathrm{CI}=19.6-26.2 \%)$ and decreased (with some fluctuation) to $11.2 \%(95 \% \mathrm{CI}=10.2-12.4 \%)$ in 2013. Prevalence rose slightly in 2014, but the overall downward trend continued to $12.9 \%(95 \% \mathrm{CI}=11.8-14.1 \%$; Table 1). In terms of regional distribution among 19
Table 1 Number of patients infected with Strongyliodes stercoralis and total specimens for diagnosis classified by year ${ }^{a}$

\begin{tabular}{lll}
\hline Years & $\begin{array}{l}\text { Number of patients } \\
\text { infected with S. stercoralis } \\
\text { (Total specimen for diagnosis) }\end{array}$ & $\begin{array}{l}\text { Diagnostic Prevalence } \\
(95 \% \mathrm{Cl})\end{array}$ \\
\hline 2004 & $144(632)$ & $22.8(19.6-26.2)$ \\
2005 & $305(1361)$ & $22.4(20.2-24.7)$ \\
2006 & $332(1723)$ & $19.3(17.4-21.2)$ \\
2007 & $448(2000)$ & $22.4(20.6-24.3)$ \\
2008 & $366(2122)$ & $17.2(15.7-18.9)$ \\
2009 & $364(2283)$ & $15.9(14.5-17.5)$ \\
2010 & $444(2519)$ & $17.6(16.2-19.2)$ \\
2011 & $369(2762)$ & $13.4(12.1-14.7)$ \\
2012 & $421(2891)$ & $14.6(13.3-15.9)$ \\
2013 & $383(3405)$ & $11.2(10.2-12.4)$ \\
2014 & $433(3346)$ & $12.9(11.8-14.1)$ \\
\hline
\end{tabular}

${ }^{a}$ Number of patients diagnosed by the FECT classified by year some repeated patients included in each studied year

${ }^{b}$ The average diagnostic prevalence was $24.11 \%$ which decreased $1.15 \%$ each year from 2004 to 2014; Regression equation: $Y=24.11-1.15 x i(95 \% \mathrm{Cl}=-1.49$ to -0.8$)$

provinces, the diagnostic prevalence was highest in Srisaket province at $24.3 \%(95 \% \mathrm{CI}=18.1-31.4 \%)$ and lowest in Nakhon Ratchasima province at $11.0 \%$ $(95 \% \mathrm{CI}=8.1-14.5 \%$; Fig. 1$)$. In terms of gender, $23.7 \%$ $(2741 / 11,589 ; 95 \%$ CI $=22.9-24.4 \%)$ of S. stercoralis positive stool belonged to males and $10.7 \%(1148 / 10,749$; $95 \%$ CI $=10.1-11.3 \%$ ) belonged to females. The higher proportion of infection in males appeared to be constant throughout the 11-year period. The mean age $( \pm S D)$ of patients was $54.4( \pm 15.7$; range $=3-96)$ years. Diagnostic prevalence was found to increase with age and reached a peak of $25.9 \%(95 \% \mathrm{CI}=24.5-27.3 \%)$ among patients who were $51-60$ years of age (Fig. 2).

\section{Discussion}

The global prevalence of S. stercoralis infection ranges from $10 \%$ to $40 \%$ [2], and is higher in countries in tropical and subtropical areas with hot and humid climates $[2,12]$. Northeast Thailand is located in the equator zone, and the average high temperatures in the cool, rainy, and summer seasons are $30.6{ }^{\circ} \mathrm{C}, 32.6{ }^{\circ} \mathrm{C}$, and $35.2{ }^{\circ} \mathrm{C}$, respectively [13]. The climate is, thus, congruent with the high prevalence of infection in this area. Previous reports performed in selected communities using different stool examination techniques showed varying prevalence of $S$. stercoralis infection, depending on the sensitivity of the method employed. A direct simple smear, for example, yielded a prevalence of $11.2 \%$ [14], while the FECT gave results that ranged from $5.4 \%$ to $10.5 \%[9,10]$, and APC results ranged from $15.9 \%$ to $28.9 \%$ [7-9]. In hospital-based studies in Thailand, diagnostic prevalences have ranged from $2.5 \%$ to $17.6 \%$ [6, 


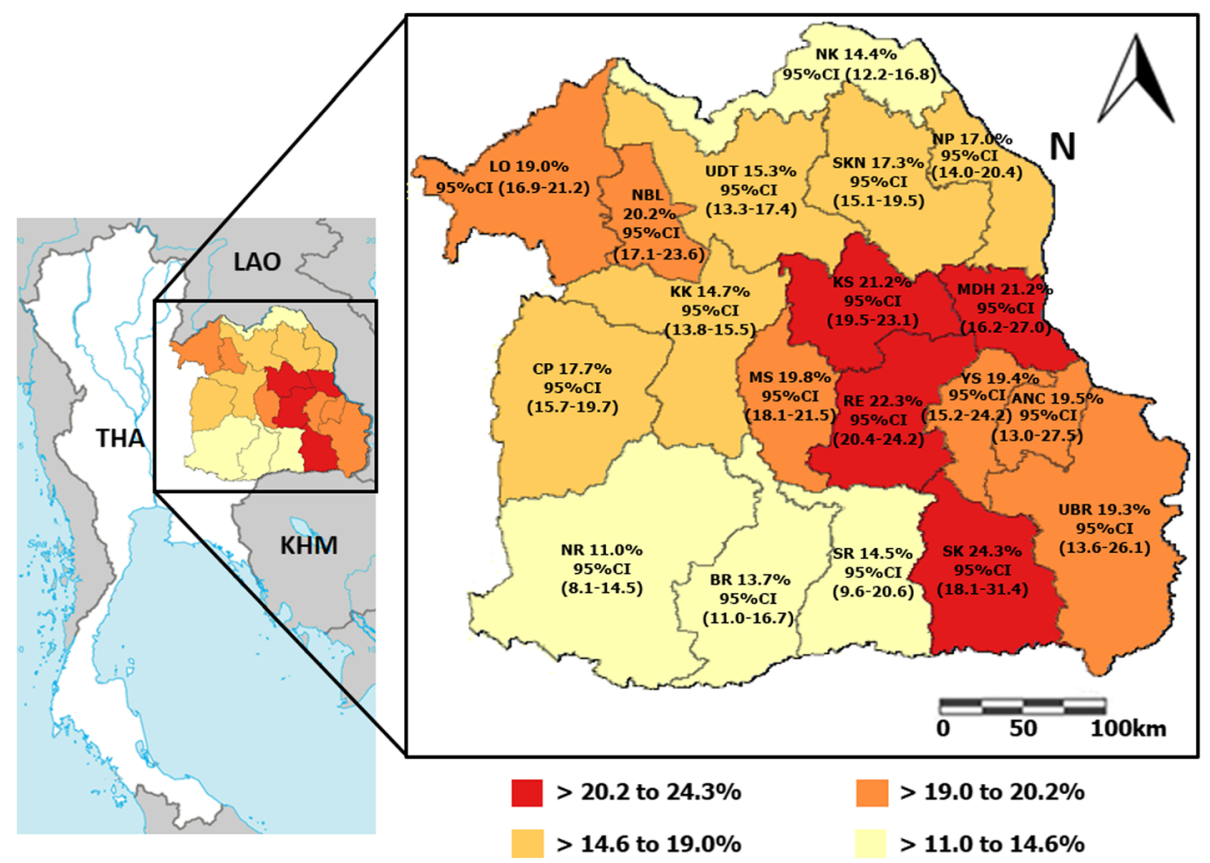

Fig. 1 Diagnostic prevalence of Strongyloides stercoralis infection by FECT in 19 provinces in northeast Thailand. The map of Thailand was modified from a map in The World Factbook, published by the Central Intelligence Agency [Central Intelligence Agency [US]. The World Factbook is available at: https://www.cia.gov/library/publications/resources/the-world-factbook/geos/th.html Accesed 1 July 2017]. Remark; ANC = Amnat Charoen, BR = Buriram, CP = Chaiyaphum, KS = Kalasin, KK = Khon Kaen, LO = Loei, MS = Maha Sarakham, MDH = Mukdahan, NP = Nakhon Phanom, NR = Nakhon Ratchasima, NBL = Nong Bua Lamphu, NK = Nong Khai, RE = Roi Et, SKN = Sakon Nakhon, SK = Sisaket, SR = =Surin, UBR $=$ Ubon Ratchathani, UDT $=$ Udon Thani and YS $=$ Yasothon. Classified group by quartiles

15]. The diagnostic prevalence of S. stercoralis infection in northeast Thailand found in this report also falls within that range at $17.4 \%(95 \% \mathrm{CI}=16.9-17.9 \%)$. Additionally, Srisaket province was found to have the highest diagnostic prevalence at $24.3 \%(95 \% \mathrm{CI}=18.1-31.4 \%)$, followed by Roi Et province at $22.3 \%(95 \% \mathrm{CI}=20.4-$
$24.2 \%)$, Kalasin province at $21.2 \%(95 \% \mathrm{CI}=19.5-23.1 \%)$ and Mukdahan province at $21.2 \%(95 \% \mathrm{CI}=16.2-27.0 \%)$. These findings are in agreement with a previous community-based study in which a high prevalence rate was found in Kalasin Province (61.0\%) [5]. This could reflect poor personal hygiene in these areas, as inadequate

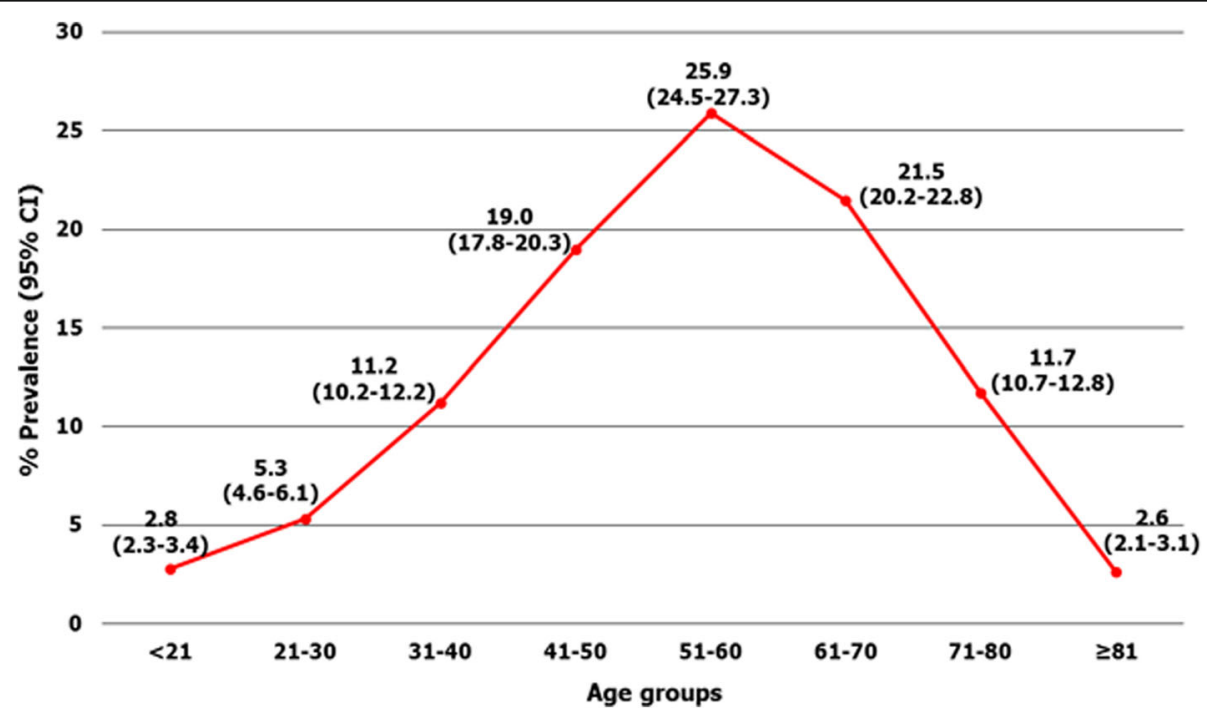

Fig. 2 Diagnostic prevalence of Strongyloides stercoralis infection classified by age group 
hygienic habits have been shown to be epidemiological factors of strongyloidiasis [12].

In Thailand, the diagnostic prevalence of $S$. stercoralis infection reported in hospital-based studies (34.7\%) has been higher than that in community-based studies (23.7\%) [2]. This could be due in part to the moderate to high sensitivity of $S$. stercoralis detection techniques performed in hospital laboratories. Moreover, hospital patients tend to be at higher risk and more likely to suffer from underlying diseases including S. stercoralis infection [2]. In addition, these patients were able to provide more than one sample for repeated examination. One advantage of a hospitalbased study is that patients come from all areas in the region, providing researchers a broad range patient data as well as saving on survey costs compared to communitybased studies $[2,16]$. Our hospital-based study was, thus, able to provide additional data on the epidemiology of human strongyloidiasis in this area.

The high diagnostic prevalence of strongyloidiasis in this area could also be due to environmental factors, such as lower organic carbon content in the soil and land-use conversion from forest to cropland [17, 18]. The main occupation of people in northeast Thailand is farming, especially rice farming. Land in this region has, thus, been converted from forest to cropland to a greater extent than in other areas [19].

The diagnostic prevalence of human strongyloidiasis in northeast Thailand found in this study means the area can be classified as highly endemic ( $>5 \%)$ [12], but is less so than its neighboring countries, Cambodia and Lao People's Democratic Republic (Lao PDR) [17, 20, 21]. Northern Cambodia has been shown to have an S. stercoralis infection rate of $44.7 \%$ [17], and the infection rate in Lao PDR has been reported at $41.0 \%$. Both of these reports were community-based and utilized the APC method $[20,21]$. This is not unexpected since the APC method is about four times more sensitive than the FECT [10]. However, if we had performed a true prevalence study in the community using APC rather than a diagnostic prevalence study based on hospital results using the FECT, we may have found a prevalence in northeast Thailand approaching those reported for Laos and Cambodia.

The finding in this study that males were at a higher risk for $S$. stercoralis infection than females corresponded with the results of previous community-based study in Cambodia and a hospital-based study in Thailand $[6,22]$. This may be due in part to occupational risks, as a greater proportion of men work in muddy rice fields without footwear, whereas a greater proportion of women work as housewives and wear shoes while walking around in their houses and villages [22]. The direct skin contact with soil that results from walking around barefoot and poor sanitary standards are both risk factors for infective larvae penetration [2]. Interestingly, our study reported the mean age $( \pm S D)$ of strongyloidiasis patients to be $54.4 \pm 15.7$, and the highest prevalence of infection (25.9\%; $95 \% \mathrm{CI}=24.5-27.3 \%)$ to be in patients 51-60 years of age. This finding is supported by a Brazilian study, which showed that the prevalence of $S$. stercoralis increased with patients' age, reaching $12.1 \%$ among people older than 60 years [12]. In Cambodia, S. stercoralis prevalence has also been shown to increase with age, growing exponentially during the first eight years of life, then slowly increasing through remaining years, reaching $51.2 \%$ in people 50 years old or older [17]. This is possibly be due to the autoinfective lifecycle, which leads to lifelong infection in almost all patients. Because infection is lifelong, the prevalence of strongyloidiasis incrementally increases with age. This is simply due to the length of time a person has to be exposed to the infection in their environment. The older populations possible have had more time to be exposed and infected. However, the data showed decreasing diagnostic prevalence in patients after they reach the age of 60 (Fig. 2). This result cannot explain, one reason may be the immune systems in most people over the age of 50 with chronic Strongyloides infection controlling the infection to the point where larval burden is so low that it cannot be detected by the insensitive FECT method.

\section{Conclusions}

In conclusion, the high prevalence of strongyloidiasis in northeast Thailand found in this study and that of neighboring countries should be emphasized by the national helminth control program and health education campaigns. Nationwide assessments of S. stercoralis infection including risk factors, treatment, and prevention should also be conducted. Developing a control strategy is important for the prevention of serious morbidity, which can result from hyperinfection or disseminated strongyloidiasis. However, the data suggest that there has been a gradual decrease in $S$. stercoralis diagnostic prevalence by year (Table 1 ), which cannot be accurately explained. It is possibly due to the effect of increases in the population's level of health education.

Nevertheless, due to the limitations of the relatively insensitive FECT and the population that was studied, the diagnostic prevalence data reported here is not completely reflective of the true community prevalence. The people screened in the hospital may represent a selected sub population (i.e. those who can afford hospital care, have gastrointestinal symptoms, and have a high larval load). Moreover, although hospital diagnoses such as those presented here are useful in identifying the comparative prevalence and burden of the disease by district and any foci of infection within districts, it may not 
reflect the actual prevalence percentages (overall and in each district). These may be shown to differ from (and possibly be higher than) the data reported here if a proper prevalence study using a highly sensitive method and multiple stool examinations per subject were to be performed on a community-wide basis.

\section{Abbreviations}

'C: Degree Celsius; 95\%Cl: 95\% confidence interval; APC: Agar plate culture; FECT: Formalin ethyl acetate concentration technique; Lao PDR: Lao People's Democratic Republic; SD: Standard deviation

\section{Acknowledgements}

We wish to acknowledge the support of the English Consultation Clinic at the Khon Kaen University Faculty of Medicine Research Affairs Division and the Khon Kaen University Publication Clinic at the Research and Technology Transfer Affairs Division for their assistance.

\section{Funding}

This study was supported by a TRF Senior Research Scholar Grant, Thailand Research Fund grant number RTA5880001; the Higher Education Research Promotion and National Research University Project of Thailand, Office of the Higher Education Commission, Thailand, through the Health Cluster (SHePGMS); the Faculty of Medicine, Khon Kaen University (grant number TR57201) through WM and PM. OS was supported by Scholarship under the PostDoctoral Training Program from Research Affairs and Graduate School, Khon Kaen University (58101). The findings and conclusions in this report are those of the authors and do not necessarily represent the official position of the funding agencies.

\section{Availability of data and materials}

The data that support the findings of this study are available at Srinagarind Hospital but restrictions apply to the availability of these data, which were used under license for the current study, and are not publicly available. Data are however available from the authors upon reasonable request and with the permission of Srinagarind Hospital.

\section{Authors' contributions}

TKP, PL, PM, WK, and WM conceived of the idea and participated in the design of this study. TKP, PorL, KS and SN conducted the study. TKP, PL, PM, WK, RK, OS, and WM were responsible for the interpretation of the results and drafting of the manuscript and reading for intellectual contents. All authors read and approved the final manuscript.

\section{Authors' information}

Not applicable.

\section{Ethics approval and consent to participate}

Ethical approval without patient informed consent for this de-identified retrospective medical record review was obtained from the Khon Kaen University Ethics Committee for Human Research (HE581354).

\section{Consent for publication}

Not applicable.

\section{Competing interests}

The authors declare that they have no competing interests.

\section{Publisher's Note}

Springer Nature remains neutral with regard to jurisdictional claims in published maps and institutional affiliations.

\section{Author details}

'Department of Parasitology, Faculty of Medicine, Khon Kaen University, Khon Kaen, Thailand. ${ }^{2}$ Department of Public Health Administration, Health Promotion, Nutrition, Faculty of Public Health, Khon Kaen University, Khon Kaen, Thailand. ${ }^{3}$ Department of Computer Engineering, Faculty of Engineering, Khon Kaen University, Khon Kaen, Thailand. ${ }^{4}$ Research and
Diagnostic Center for Emerging Infectious Diseases, Mekong Health Science Institute, Khon Kaen University, Khon Kaen, Thailand.

Received: 8 February 2017 Accepted: 8 September 2017

Published online: 18 September 2017

\section{References}

1. Nutman TB. Human infection with Strongyloides stercoralis and other related Strongyloides species. Parasitology. 2016:1-11.

2. Schär F, Trostdorf U, Giardina F, Khieu V, Muth S, Marti H, Vounatsou P, Odermatt P. Strongyloides stercoralis: Global Distribution and Risk Factors. PLoS Negl Trop Dis. 2013;7:e2288

3. Olsen $A$, van Lieshout $L$, Marti H, Polderman T, Polman K, Steinmann $P$, Stothard R, Thybo S, Verweij JJ, Magnussen P. Strongyloidiasis-the most neglected of the neglected tropical diseases? Trans R Soc Trop Med Hyg. 2009:103:967-72.

4. Beknazarova M, Whiley H, Ross K. Strongyloidiasis: A Disease of Socioeconomic Disadvantage. Int J Environ Res Public Health. 2016;13 https://doi.org/10.3390/ ijerph13050517. pii: E517

5. Jongsuksuntigul P, Intapan PM, Wongsaroj T, Nilpan S, Singthong S, Veerakul S, Maleewong W. Prevalence of Strongyloides stercoralis infection in northeastern Thailand (agar plate culture detection). J Med Assoc Thail. 2003;86:737-41.

6. Jongwutiwes U, Waywa D, Silpasakorn S, Wanachiwanawin D, Suputtamongkol Y. Prevalence and risk factors of acquiring Strongyloides stercoralis infection among patients attending a tertiary hospital in Thailand. Pathog Glob Health 2014;108:137-40

7. Nontasut P, Muennoo C, Sa-nguankiat S, Fongsri S, Vichit A. Prevalence of Strongyloides in Northern Thailand and treatment with ivermectin vs albendazole. SE Asian J Trop Med Public Health. 2005;36:442-4.

8. Sithithaworn J, Sithithaworn P, Janrungsopa T, Suvatanadecha K, Ando K, Haswell-Elkins MR. Comparative assessment of the gelatin particle agglutination test and an enzyme-linked immunosorbent assay for diagnosis of strongyloidiasis. J Clin Microbiol. 2005;43:3278-82.

9. Sithithaworn P, Srisawangwong T, Tesana S, Daenseekaew W, Sithithaworn J, Fujimaki Y, Ando K. Epidemiology of Strongyloides stercoralis in north-east Thailand: application of the agar plate culture technique compared with the enzyme-linked immunosorbent assay. Trans R Soc Trop Med Hyg. 2003:97:398-402.

10. Intapan PM, Maleewong W, Wongsaroj T, Singthong S, Morakote N. Comparison of the quantitative formalin ethyl acetate concentration technique and agar plate culture for diagnosis of human strongyloidiasis. J Clin Microbiol. 2005:43:1932-3.

11. Elkins DB, Haswell-Elkins M, Anderson RM. The epidemiology and control of intestinal helminths in the Pulicat Lake region of Southern India. I. Study design and pre- and post-treatment observations on Ascaris lumbricoides infection. Trans R Soc Trop Med Hyg. 1986;80:774-92.

12. Paula F, Costa-Cruz J. Epidemiological aspects of strongyloidiasis in Brazil. Parasitology. 2011;138:1331-40.

13. Meteorological Department of Thailand. Ministry of Digital Economy and society. Thailand. 2014. http://www.tmd.go.th/info/info.php?FilelD=22. Accessed 20 Sept 2016. [In Thai].

14. Kasuya S, Khamboonruang C, Amano K, Murase T, Araki H, Kato Y, Kumada Y, Koyama A, Higuchi M, Nakamura J, Tomida K, Makino S. Intestinal parasitic infections among schoolchildren in Chiang Mai, northern Thailand: an analysis of the present situation. J Trop Med Hyg. 1989:92:360-4.

15. Jongwutiwes $S$, Charoenkorn M, Sitthichareonchai $P$, Akaraborvorn $P$, Putaporntip C. Increased sensitivity of routine laboratory detection of Strongyloides stercoralis and hookworm by agar-plate culture. Trans R Soc Trop Med Hyg. 1999;93:398-400.

16. Martinez-Perez A, Lopez-Velez R. Is strongyloidiasis endemic in Spain? PLoS Negl Trop Dis. 2015;9:e0003482.

17. Khieu V, Schär F, Forrer A, Hattendorf J, Marti H, Duong S, Vounatsou P, Muth S, Odermatt P. High prevalence and spatial distribution of Strongyloides stercoralis in rural Cambodia. PLoS Negl Trop Dis. 2014;8:e2854.

18. Wall DH, Nielsen UN, Six J. Soil biodiversity and human health. Nature. 2015; 528:69-76.

19. Office of agricultural economics. Ministry of Agriculture and Cooperatives. Thailand. 2016. http://www.oae.go.th/download/download_journal/2558/ yearbook57.pdf. Accessed 20 Sep 2016. [In Thai]. 
20. Laymanivong S, Hangvanthong B, Insisiengmay B, Vanisaveth V, Laxachack P, Jongthawin J, Sanpool O, Thanchomnang T, Sadaow L, Phosuk I, Rodpai R, Maleewong W, Intapan PM. First molecular identification and report of genetic diversity of Strongyloides stercoralis, a current major soil-transmitted helminth in humans from Lao People's Democratic Republic. Parasitol Res. 2016;115:2973-80.

21. Vonghachack Y, Sayasone S, Bouakhasith D, Taisayavong K, Akkavong K, Odermatt P. Epidemiology of Strongyloides stercoralis on Mekong islands in southern Laos. Acta Trop. 2015;141:289-94.

22. Khieu V, Schär F, Marti H, Bless PJ, Char MC, Muth S, Odermatt P. Prevalence and risk factors of Strongyloides stercoralis in Takeo Province, Cambodia. Parasit Vectors. 2014;7:221-8.

Submit your next manuscript to BioMed Central and we will help you at every step:

- We accept pre-submission inquiries

- Our selector tool helps you to find the most relevant journal

- We provide round the clock customer support

- Convenient online submission

- Thorough peer review

- Inclusion in PubMed and all major indexing services

- Maximum visibility for your research

Submit your manuscript at www.biomedcentral.com/submit
Biomed Central 